\title{
El pluralismo social en la jurisprudencia de la Corte Constitucional colombiana y sus efectos en la realización efectiva de los derechos ${ }^{*}$
}

Social pluralism in the jurisprudence of Colombian Constitutional Court and its effects on the effective realization of rights

\author{
Édgar Antonio Guarin Ramirez ${ }^{* *}$ \\ Luisa Fernanda Olarte López $z^{* * *}$ \\ Juan Sebastián Garzón Barrera ${ }^{* * *}$
}

Fecha de recepción: 12 de octubre de 2018

Fecha de aprobación: 18 de enero de 2019

* $\quad$ Este artículo presenta los resultados de un proyecto de investigación aprobado por Fodein y ejecutado en 2016 por investigadores del semillero de Filosofía y Teoría del Derecho de la Universidad Santo Tomás, vinculado al Grupo Raimundo de Peńafort, dentro de la línea de Filosofía, Teoría e Historia del Derecho. Proyecto de investigación "Desarrollo del concepto de pluralismo en la jurisprudencia de la Corte Constitucional colombiana: un análisis crítico a partir del marco teórico aportado por el realismo jurídico aristotélico-tomista”. Citar como Guarín Ramírez, E., Olarte López, L. y Garzón Barrera, J. (2019). El pluralismo social en la jurisprudencia de la corte constitucional colombiana y sus efectos en la materialización de los derechos. Via Inveniendi et Iudicandi, 14(2), 11-34. Doi: https://doi.org/10.15332/19090528.5046

** Doctor en Derecho. Docente, investigador, director del semillero de Filosofía y Teoría del Derecho de la Universidad Santo Tomás, Bogotá, Colombia. Correo electrónico: edgarguarin@usantotomas.edu.co. Orcid: https://orcid.org/0000-0002-3329-1591

*** Estudiante investigadora del semillero de Filosofía y Teoría del Derecho de la Universidad Santo Tomás, Bogotá, Colombia. Correo electrónico: luisaolarte@usantotomas.edu.co. Orcid: https://orcid. org/0000-0002-4670-1158

**** Estudiante investigador del semillero de Filosofía y Teoría del Derecho de la Universidad Santo Tomás, Bogotá, Colombia. Correo electrónico: sebatiangarzón@usantotomas.edu.co. Orcid: https://orcid. org/0000-0003-2907-6781 


\section{RESUMEN}

A partir de los desarrollos en torno al concepto de pluralismo social el alto tribunal de lo constitucional en Colombia ha abierto la puerta al reconocimiento de derechos a sectores de la población que durante mucho tiempo fueron excluidos: indígenas, afrodescendientes, comunidades rom, etc. Empero, dichos desarrollos también han conducido a una defensa de las convicciones personales de cada individuo — erigidas como derechos a través del concepto de libre desarrollo de la personalidad - , cuyo ejercicio en ocasiones interfiere con derechos legítimamente constituidos de otras personas, lo cual es causa de confrontación social. Los enconados debates en casos como los de la eutanasia, el aborto, las uniones entre parejas del mismo sexo, la dosis personal, entre otros, son muestra de ello. Jurídicamente la problemática se relaciona con temas que refieren al concepto mismo de derecho y los elementos que lo estructuran, la recta administración de justicia, el papel de los jueces constitucionales y la conservación del orden social como un bien común.

Palabras clave: administración de justicia, derechos, dignidad humana, libertad, pluralismo social.

\section{Abstract}

Based on developments around the concept of social pluralism, the high constitutional court in Colombia has opened the door to the recognition of rights to sectors of the population that have been excluded for a long time: Indigenous, Afro-descendants, Rom communities, etc. However, such developments have also led to a defense of the personal convictions of each individual — as rights through the concept of free development of personality —, whose exercise sometimes interferes with the "rights" of other legitimately constituted persons, which is the cause of social confrontation. Bitter debates in cases such as euthanasia, abortion, unions of same-sex couples, personal dose, among others, are examples of this. Juridically the problem relates to issues that refer to the very concept of right, and the elements that structure it, the correct administration of justice, the role of constitutional judges and the maintenance of social order as a common good.

Keywords: Administration of justice, rights, human dignity, freedom, Social pluralism. of learning, extra-age, culture of peace. 
Édgar Antonio Guarín Ramírez, Luisa Fernanda Olarte López, Juan Sebastián Garzón Barrera El pluralismo social en la jurisprudencia de la Corte Constitucional colombiana y sus efectos en la realización efectiva de los derechos

\section{INTRODUCCIÓN}

El artículo primero de la Constitución Nacional establece que

Colombia es un Estado social de derecho, organizado en forma de República unitaria, descentralizada, con autonomía de sus entidades territoriales, democrática, participativa y pluralista, fundada en el respeto de la dignidad humana, en el trabajo y la solidaridad de las personas que la integran y en la prevalencia del interés general. (Énfasis añadido)

Según la Corte Constitucional colombiana la adjetivación del Estado como pluralista

[...] se conecta al menos con tres dimensiones: ser el reflejo de una sociedad que (i) admite y promueve de manera expresa el hecho de la diversidad (artículo 7o Superior) (ii) aprecia de modo positivo las distintas aspiraciones y valoraciones existentes hasta el punto de proteger de modo especial la libertad religiosa de conciencia y pensamiento, así como la libertad de expresión, y (iii) establece los cauces jurídicos, políticos y sociales que servirán para dirimir los posibles conflictos que se presenten en virtud de las diferencias vigentes en un momento determinado. (Sentencia T-388/2009)

La problemática que dio origen a la investigación que está a la base de este artículo surge por el hecho de que el alto tribunal de lo constitucional, invocando el pluralismo, hace una defensa de la autonomía individual, cuyo respeto es casi irrestricto. Con ello genera un ámbito de protección infranqueable a las propias convicciones, sean de orden ideológico, religioso o moral, lo que las erige en derechos fundamentales (Abellán, 1990, p. 202). Así, el nexo entre pluralismo social y libertad se hace cada vez más grande, hasta el punto de poder afirmar que el respeto por las libertades y por el libre desarrollo de la personalidad deviene uno de los corolarios más importantes del artículo primero constitucional cuando refiere a Colombia como un Estado pluralista. De este modo, se potencia de tal forma lo individual que cualquier intento de establecer principios sociales rectores de carácter supraindividual es sometido al más estricto escrutinio. En dicha eventualidad el Estado debe portar 
sólidos argumentos que justifiquen una intervención en el campo de lo individual, el cual en principio es inmune a cualquier interferencia (Sentencia C-355/2006).

Con base en estos presupuestos teóricos la Corte Constitucional se ha convertido en garante de derechos de grupos poblacionales tradicionalmente marginados. Empero, a la par, la defensa de la autonomía individual — bajo el amparo de la interpretación que se hace, entre otros, del artículo 16 de la Constitución Nacional — la ha llevado a considerar algunas convicciones personales como derechos, a menos que con ellas, según lo ha advertido, se afecten el ordenamiento jurídico y los derechos de otros. Esto genera una confrontación de "derechos" que se traduce en confrontación social.

Para precisar el significado del concepto de pluralismo en la Corte Constitucional, se compendiaron y analizaron fallos emanados por ese tribunal entre 2005 y 2015 . Y para ahondar en los elementos que integran el derecho se hizo uso del marco teórico aportado por el realismo clásico mediante el análisis de fuentes primarias como la Ética nicomáquea y la Politica, de Aristóteles, y el De regno y la Suma teológica, de Tomás de Aquino. Además, se estudiaron fuentes secundarias como el Tratado de la virtudes, de Josef Pieper; el Realismo metódico, de Étienne Gilson; el Compendio de filosofía del derecho, de Michel Villey, y las Lecciones propedéuticas de filosofía del derecho, del profesor espańol Javier Hervada, entre otras.

Para la presentación de las ideas este artículo se ha dividido en dos partes: la caracterización del concepto de pluralismo social en la Corte Constitucional y la crítica que emerge del realismo jurídico clásico a dicha caracterización. En la segunda parte las proposiciones del alto tribunal se someten a la prueba de realidad, criterio de juicio fundamental del sistema de pensamiento realista, para determinar los efectos de dicha caracterización en la materialización de los derechos.

\section{CARACTERIZACIÓN DEL CONCEPTO DE PLURALISMO SOCIAL en la Corte Constitucional}

A pesar de que el principio de pluralismo social es solo uno, su desarrollo por parte de la Corte Constitucional se ha manifiestado en varios aspectos de la vida social, los cuales 
Édgar Antonio Guarín Ramírez, Luisa Fernanda Olarte López, Juan Sebastián Garzón Barrera El pluralismo social en la jurisprudencia de la Corte Constitucional colombiana y sus efectos en la realización efectiva de los derechos

intrínsecamente lo expresan desde diferentes ópticas. Por eso es necesario analizar dichos aspectos para poder entender el sentido y alcance que el alto tribunal le ha dado a ese significante, cuyas repercusiones sociales son particularmente importantes por su trascendencia en la vida personal y social de quienes conforman el Estado colombiano. En la Sentencia T-388/2009 la Corte afirma que la fórmula pluralista se manifiesta en tres dimensiones: i) la diversidad que se admite y promueve; ii) las distintas aspiraciones y valoraciones que se aprecian de modo positivo, de manera especial las libertades religiosa, de conciencia y de pensamiento, así como la libertad de expresión, y iii) los cauces jurídicos, políticos y sociales que servirán para dirimir los posibles conflictos que se presenten en virtud de la diferentes concepciones. Estas tres dimensiones del pluralismo tienen su fundamento en la dignidad humana, según se ha expresado. Por eso es menester referir a estos aspectos que integran el concepto de pluralismo (Rodríguez, 2016).

Sobre la dignidad humana como soporte del pluralismo hay dos aspectos importantes que precisar: el primero, la significación que la Corte le ha dado; el segundo, las razones para que se constituya en base ineluctable del pluralismo social. En lo que refiere al primer aspecto la Corte, en Sentencia T-881/2002 con Eduardo Montealegre como magistrado ponente, esgrime las tres interpretaciones posibles de la dignidad:

(i) La dignidad humana entendida como autonomía o como posibilidad de diseñar un plan vital y de determinarse según sus características (vivir como cada uno quiera). (ii) La dignidad humana entendida como ciertas condiciones materiales concretas de existencia (vivir bien). Y (iii) la dignidad humana entendida como intangibilidad de los bienes no patrimoniales, integridad física e integridad moral (vivir sin humillaciones) (Sentencia T-881/2012).

En materia de pluralismo social el alcance del concepto de dignidad es particularmente importante en lo que refiere a vivir como cada uno quiera y sin humillaciones. Cabe señalar que la Corte ha puesto lo segundo como una consecuencia de lo primero. Esto es, el diseño de un plan de vida totalmente autónomo y libre por parte de un individuo - conforme a sus convicciones y anhelos, sin que exista posibilidad de ser objeto de algún reproche, estigma o señalamiento por parte de otros que 
no compartan esta misma manera de ser- es condición para vivir con dignidad (Guarín, 2013).

En la precitada sentencia la Corte también formula las razones fundamentales en las que encuentra asidero la dignidad humana como base del pluralismo social:

Al tener como punto de vista la funcionalidad, del enunciado normativo "dignidad humana", la Sala ha identificado tres lineamientos: (i) la dignidad humana entendida como principio fundante del ordenamiento jurídico y por tanto del Estado, y en este sentido la dignidad como valor. (ii) La dignidad humana entendida como principio constitucional. Y (iii) la dignidad humana entendida como derecho fundamental autónomo. (Sentencia T-881/2002)

Así pues, la dignidad humana en Colombia es valor, principio y derecho, con lo cual la Corte ha querido poner de presente su relevancia dentro del ordenamiento jurídico y la vida social en general (Aldana y Guarín, 2016). Sobre esta base epistemológica se funden dignidad y libertad, entendida esta última como "vivir como cada uno quiera", con las limitaciones propias que representan el ordenamiento jurídico y los derechos ajenos. La interpretación de la Corte respecto de lo que significa que Colombia sea un Estado pluralista ha conducido pues a la afirmación de la defensa de las libertades como la mayor manifestación de dicho pluralismo y, especialmente, de la libertad moral expresada a través de la expresión "libre desarrollo de la personalidad". Esta libertad, ha dicho la Corte, es el eje gravitacional sobre el que giran todos los demás derechos fundamentales, incluido el de la vida humana. Hasta 1997 parte de los límites a la libertad era el respeto por la vida; empero, en la Sentencia C-293/1997, que trató sobre la constitucionalidad del art. 326 del Código Penal (C. P.) — regulador del homicidio por piedad-, comenzó una línea de pensamiento según la cual el Estado no puede pretender proteger la vida de las personas desconociendo su autonomía y su dignidad. Esta dignidad, dice el fallo, encuentra su máxima expresión en el derecho al libre desarrollo de la personalidad, al permitir que sean los individuos los que elijan en qué condiciones vivir. En el texto contentivo de la providencia se dice: 
Édgar Antonio Guarín Ramírez, Luisa Fernanda Olarte López, Juan Sebastián Garzón Barrera El pluralismo social en la jurisprudencia de la Corte Constitucional colombiana y sus efectos en la realización efectiva de los derechos

La Constitución establece que el Estado colombiano está fundado en el respeto a la dignidad de la persona humana; esto significa que, como valor supremo, la dignidad irradia el conjunto de derechos fundamentales reconocidos, los cuales encuentran en el libre desarrollo de la personalidad su máxima expresión. El principio de la dignidad humana atiende necesariamente a la superación de la persona, respetando en todo momento su autonomía e identidad. (Sentencia C-355/2006)

De esta forma, si una persona decide acabar con sus padecimientos ante una enfermedad terminal, el médico que ayude a lograr el fin de tales dolores por medio de la muerte no podrá ser juzgado conforme al artículo $326 \mathrm{del} \mathrm{C.} \mathrm{P.} \mathrm{Y} \mathrm{más} \mathrm{adelante}$ se afirma:

La Constitución se inspira en la consideración de la persona como un sujeto moral, capaz de asumir en forma responsable y autónoma las decisiones sobre los asuntos que en primer término a él incumben, debiendo el Estado limitarse a imponerle deberes, en principio, en función de los otros sujetos con quienes está abocado a convivir, y por tanto, si la manera en que los individuos ven la muerte refleja sus propias convicciones, ellos no pueden ser forzados a continuar viviendo cuando, por las circunstancias extremas en que se encuentran, no lo estiman deseable ni compatible con su propia dignidad, con el argumento inadmisible de que una mayoría lo juzga un imperativo religioso o moral. De nadie puede el Estado demandar conductas heroicas, menos aún si el fundamento de ellas está adscrito a una creencia religiosa o a una actitud moral que, bajo un sistema pluralista, sólo puede revestir el carácter de una opción. Nada tan cruel como obligar a una persona a subsistir en medio de padecimientos oprobiosos en nombre de creencias ajenas, así una inmensa mayoría de la población las estime intangibles. Porque, precisamente, la filosofía que informa la Carta se cifra en su propósito de erradicar la crueldad. Desde una perspectiva pluralista no puede afirmarse el deber absoluto de vivir. Quien vive como obligatoria una conducta, en función de sus creencias religiosas o morales, no puede pretender que ella se haga coercitivamente exigible a todos; solo que a él se le permita vivir su vida moral plena y actuar en función de ella sin interferencias. Además, si el 
respeto a la dignidad humana irradia el ordenamiento, es claro que la vida no puede verse simplemente como algo sagrado, hasta el punto de desconocer la situación real en la que se encuentra el individuo y su posición frente al valor de la vida para sí. En palabras de esta Corte: el derecho a la vida no puede reducirse a la mera subsistencia, sino que implica el vivir adecuadamente en condiciones de dignidad. (Sentencia C-239/1997)

Así pues, para la Corte solamente el titular del derecho a la vida puede decidir hasta cuándo es esta deseable y compatible con su dignidad como humano. Hablar de la vida como algo "sagrado" corresponde a una visión religiosa incompatible con el pluralismo social. De esta forma, queda sentada la tesis según la cual el deber del Estado de proteger la vida ha de ser entonces compatible con el respeto a la dignidad humana entendida fundamentalmente como respeto por el libre desarrollo de la personalidad.

A partir de la década de 2000 la Corte siguió la línea que une la dignidad y la libertad de vivir como cada quien quiera, especialmente en las sentencias que tuvieron como magistrado ponente a Jaime Araújo Rentería. Para citar un caso está la Sentencia C-098/2003, en donde se analiza la constitucionalidad de unos artículos del estatuto del abogado en los cuales se tipificaban algunas faltas contra la dignidad de la profesión. Allí se confirma la tesis de no intervención estatal en actos tales como la embriaguez o la visita a lugares de lenocinio, entre otros, en razón de que tales prohibiciones corresponden más a un "Estado políticamente autoritario y socialmente retardatario", antipluralista y no defensor y promotor de los derechos fundamentales, entre ellos, la libertad ${ }^{1}$. Además, el alto tribunal abiertamente proclama en ese fallo

1 Según el decir de la Corte, que un abogado esté dando espectáculos al público producto de su vida personal desordenada nada tiene que ver con el ejercicio de la profesión de abogado: corresponde a hábitos ligados a su esfera estrictamente personal, que normalmente se agotan en su mundo privado y que, por tanto, en la medida en que no interfieran en el desarrollo de su profesión ni en el respeto a las personas relacionadas con esta, tienen protección constitucional. Y recordando lo dicho en la Sentencia C-373/2002 sostuvo que "por ese motivo, aquellas particulares conducciones de vida de los servidores públicos que se explican como alternativas existenciales y que no involucran infracción de deber funcional alguno son incuestionables para la potestad disciplinaria e irrelevantes para la configuración de inhabilidades pues ni los ilícitos disciplinarios ni los impedimentos para acceder a la función pública pueden orientarse a la formación de hombres buenos y mucho menos a hacerlo de acuerdo con los parámetros de bondad que pueda irrogarse el Estado. A este le basta 
Édgar Antonio Guarín Ramírez, Luisa Fernanda Olarte López, Juan Sebastián Garzón Barrera El pluralismo social en la jurisprudencia de la Corte Constitucional colombiana y sus efectos en la realización efectiva de los derechos

el talante antropocéntrico de la Constitución colombiana. Como esta gira en torno al hombre, y este puede hacer uso de su libertad como quiera, censurar a un abogado porque su comportamiento no esté acorde con unos cánones morales socialmente aceptados afecta el derecho al libre desarrollo de su personalidad, lo cual es contrario al pluralismo social e impensable en un Estado social de derecho como el nuestro.

En esta misma línea de pensamiento, en la Sentencia T-266/2006 se dice respecto de esta relación entre libertad y dignidad, al tratar un caso de un joven que fue sometido a unos exámenes para determinar si tenía drogas en su cuerpo:

Se desbordó [por parte del colegio] el ejercicio legítimo de la función correctora y orientadora de las directivas escolares. [...] Una práctica médica, por simple que sea, como se trata de una muestra de sangre sin el consentimiento del paciente, violenta la dignidad y la integridad de la persona sobre la que se practica, más aún [...] donde la justificación fue el presunto consumo de sustancias alucinógenas. (Sentencia T-266/2006)

Con estas afirmaciones queda en el ambiente, aunque lógicamente no sea correcto inferirlo, la idea de que consumir drogas es algo acorde con la dignidad de la persona mientras que censurarlo es contrario a esta.

En otra sentencia, la T-1096/2004, la Corte sostuvo que el Instituto Nacional Penitenciario y Carcelario (Inpec) no puede imponer valores a nivel de la vivencia de la sexualidad a sus reclusos y debe respetar su proceso de reinserción social. De esta manera, proteger y garantizar la opción sexual de ellos es proteger su libre desarrollo de la personalidad como un componente fundamental de su dignidad. Con este fallo, que después ha sido replicado y ratificado en otras providencias, quedó establecido que en Colombia es antipluralista limitar la opción sexual que cada uno de los ciudadanos quiera tener.

con orientar su potestad disciplinaria al cumplimiento de los deberes funcionales de sus servidores y a asegurar la primacía del interés general en la función pública, pero no tiene ninguna legitimidad para interferir la esfera interna de cada ser humano". 
En el fallo C-355 de 2006 se recoge buena parte de las ideas que la Corte ha expresado respecto al concepto de libre desarrollo de la personalidad y su relación con la dignidad humana y el pluralismo social. Allí se dice que una mujer tiene derecho a determinar el número de hijos que quiera tener, y por ello al legislador le está prohibido invadir de manera desproporcionada tal esfera pues, de hacerlo, estaría violando el libre desarrollo de la personalidad de ella y, por ende, su dignidad. Algo impensable en un Estado pluralista y social de derecho. Además, se recoge lo ya dicho en otros fallos: que la dignidad humana es autonomía personal. Y más adelante agrega el tribunal:

La dignidad humana asegura de esta manera una esfera de autonomía y de integridad moral que debe ser respetada por los poderes públicos y por los particulares. Respecto de la mujer, el ámbito de protección de su dignidad humana incluye las decisiones relacionadas con su plan de vida, entre las que se incluye la autonomía reproductiva, al igual que la garantía de su intangibilidad moral, que tendría manifestaciones concretas en la prohibición de asignarle roles de género estigmatizantes, o infringirle [sic] sufrimientos morales deliberados. (Sentencia C-355/2006)

Para la Corte las posiciones de aquellos que expresan modelos de vida que invitan a las personas a vivir según un paradigma de perfección humana atentan contra el pluralismo social. En la Sentencia C-309/1997 el tribunal hace algunas precisiones respecto de la imposibilidad en un Estado como el colombiano, caracterizado por el pluralismo, de tener un único concepto de lo que es tal perfección:

En Colombia, las políticas perfeccionistas se encuentran excluidas, ya que no es admisible que en un Estado que reconoce la autonomía de la persona y el pluralismo en todos los campos, las autoridades impongan, con la amenaza de sanciones penales, un determinado modelo de virtud o de excelencia humana. En efecto, esas políticas implican que el Estado sólo admite una determinada concepción de realización personal, lo cual es incompatible con el pluralismo. Además, en virtud de tales medidas, las autoridades sancionan a un individuo que no ha afectado derechos de terceros, únicamente porque no acepta los ideales coactivamente establecidos por el Estado, con lo cual se vulnera la 
Édgar Antonio Guarín Ramírez, Luisa Fernanda Olarte López, Juan Sebastián Garzón Barrera El pluralismo social en la jurisprudencia de la Corte Constitucional colombiana y sus efectos en la realización efectiva de los derechos

autonomía, que etimológicamente significa precisamente la capacidad de la persona de darse sus propias normas. (Sentencia C-309/1997)

En este orden de ideas, inculcar a los ciudadanos una determinada manera de entender la perfección del hombre resulta abiertamente contrario al libre desarrollo de su personalidad, a su dignidad y al pluralismo propio de un Estado democrático como el colombiano. La siguiente frase contenida en el fallo da cuenta de ello:

La libertad de autodeterminación hace que la persona sea un fin en sí misma. La persona es dueńa de su propia "felicidad", lo que la hace digna. Por consiguiente, existe la posibilidad de rechazar las acciones externas que pretendan determinar qué es lo bueno o conveniente para un individuo. (Sentencia C-309/1997)

Sobre la base teórica expuesta en los párrafos anteriores, en el precitado fallo T-388 de 2009 el concepto de pluralismo ya no solamente se relaciona con el respeto por el libre desarrollo de la personalidad, sino que se hace extensivo al respeto por otras libertades, como la de conciencia, la religiosa o la de expresión. Respecto de la libertad de conciencia y el pluralismo, en la Sentencia SU-108/2016 afirma la Corte que "ha sido entendida como un elemento indispensable en una sociedad democrática, participativa y pluralista, que reconoce la necesidad de la autorrealización del individuo y la garantía de la dignidad humana”. Y en la Sentencia T-409/1992 la Corte indica que "la facultad que tiene una persona para actuar en determinado sentido, o para abstenerse de hacerlo, se ve determinada en grado sumo por sus convicciones, por su propia ideología, por su manera de concebir el mundo". Se trata en definitiva del propio discernimiento sobre lo que está bien y lo que está mal, tal como lo sostiene en la sentencia de constitucionalidad C-616/1997. La limitación de esta libertad de discernir y decidir sobre lo que daña o preserva sin más referente que las propias convicciones del sujeto es antipluralista, contraria a la igualdad y la tolerancia y, por tanto, inconstitucional.

En relación con el derecho a la libertad religiosa y su vinculación con el pluralismo, en la Sentencia C-948/2014, con ponencia de María Victoria Calle, la Corte dice: "la libertad religiosa protege la pluralidad de opciones que puede asumir la persona 
sobre las preguntas últimas de la existencia y el fundamento del buen vivir, sin ser objeto de injerencia alguna por parte del Estado". En ese fallo se afirma también que

[...] el pluralismo religioso, aunque está estrechamente vinculado con el concepto de Estado laico, tiene un contenido y alcance concreto. De acuerdo con esa garantía Constitucional, que se deriva del principio democrático pluralista, al igual que del derecho a la igualdad y del derecho a la libertad religiosa, las diferentes creencias religiosas tienen idéntico reconocimiento y protección por parte del Estado. (Sentencia C-984/2004)

Esta libertad es inseparable del principio de laicidad, entendido como "la neutralidad del Estado frente a las distintas religiones y la prohibición de favorecimiento a algunas de ellas", es decir, como la posición imparcial que debe adoptar el Estado en lo que respecta al reconocimiento y la protección de los diferentes credos existentes. Es manifiesta entonces la relación que hay entre el pluralismo religioso y el principio de laicidad pues al haber multiplicidad de creencias, igualdad entre ellas, e imparcialidad de trato por parte del Estado se puede desarrollar y aplicar más acertadamente la libertad de cultos. Por ello la Corte afirma que "el pluralismo religioso, la libertad de cultos y la igualdad entre las confesiones religiosas sirven de marco a la concepción de laicidad del Estado incorporada a la Carta de 1991”.

También ha sido relacionado el pluralismo social con la libertad de expresión, que en términos de la Corte consiste en

[...] el derecho de las personas a expresar y difundir libremente el propio pensamiento, opiniones, informaciones e ideas, sin limitación, a través del medio y la forma escogidos por quien se expresa. Apareja el derecho de su titular a no ser molestado por el Estado por expresar su pensamiento, opiniones, informaciones o ideas personales, y cuenta con una dimensión individual y una colectiva. (Sentencia T-391/2007)

También se dice en este fallo que 
Édgar Antonio Guarín Ramírez, Luisa Fernanda Olarte López, Juan Sebastián Garzón Barrera El pluralismo social en la jurisprudencia de la Corte Constitucional colombiana y sus efectos en la realización efectiva de los derechos

la libre manifestación y comunicación del pensamiento, así como el libre flujo social de información, ideas y opiniones, han sido erigidos en la condición indispensable de prácticamente todas las demás formas de libertad, en un prerrequisito para evitar la atrofia o el control del pensamiento, y un presupuesto cardinal de las sociedades políticas abiertas, pluralistas y democráticas. (Sentencia T-391/2007)

En síntesis, la perspectiva pluralista defendida por la Corte se enraíza en un concepto de dignidad humana según el cual la autonomía individual se convierte en criterio fundamental y eje gravitacional sobre el que giran todos los demás derechos, y por tanto, todo el ordenamiento jurídico. A partir de este criterio primigenio el tribunal desarrolla otros que relaciona directamente con el pluralismo social, como la igualdad y la tolerancia (Sentencia T-817/2011). Para la Corte un Estado pluralista propende a la coexistencia, la igualdad, el respeto y la tolerancia frente a las distintas formas de desarrollar cierto proyecto de vida personal (Sentencia T-1023/2010). En desarrollo de estos principios recientemente el tribunal avaló la unión de parejas del mismo sexo como matrimonio y les abrió la posibilidad de adoptar hijos (Sentencia SU214/2016). Según el parecer de la Corte negar este reconocimiento y posibilidad sería propio de Estados no democráticos, no pluralistas y no igualitarios.

\section{APLiCACIÓN DEL APARATO CRÍTICO DEL REALISMO JURÍDICO CLÁSICO AL CONCEPTO De PLURALISMo Social DE la CoRTe CONSTITUCIONAL Y ANÁLISIS DE SUS EFECTOS EN LA MATERIALIZACIÓN DE LOS DERECHOS}

El marco teórico por el que se optó como soporte epistemológico de la investigación en torno a la problemática señalada en la introducción de este artículo es el del realismo clásico, que en materia filosófico-jurídica ha tenido especial importancia histórica y hoy se encuentra especialmente rehabilitado en el ambienta académico mundial. Hacia 1974 surgió en el mundo un movimiento conocido como "la rehabilitación de la filosofía práctica", que ha buscado restablecer la relación entre la prudencia y la racionalidad práctica sobre la base de una noción del hombre y su dignidad soportada ontológicamente. Autores como Mounier, Bubber, Levinás, 
Burgos, en el campo de la antropología filosófica, y otros como John Finiss, Carlos Ignacio Massini, Rodolfo Vigo, Javier Hervada, Michel Villey, Michael Sandel, Alasdair MacIntyre, Maurizio Ferraris, entre otros, en el campo del derecho y la política, dan cuenta de este esfuerzo por recuperar dicha relación. El realismo, como sistema filosófico, hace parte nuclear de la tradición central de Occidente y encuentra en Aristóteles y Tomás de Aquino dos de sus más importantes sistematizadores, razón por la cual también se le conoce como realismo aristotélico-tomista. En el ámbito jurídico este realismo se conoce como realismo jurídico clásico.

Uno de los aspectos más importantes de este realismo jurídico es la posibilidad que ha abierto de buscar alternativas de solución a los problemas actuales en el ámbito de lo ético, lo político y lo jurídico, los cuales hacen parte del uso práctico de la racionalidad humana.

Para ello aplica la denominada metodología prudencial, cuyas bases teóricas están en el aristotelismo, pero que fue desarrollada por el Aquinate en la cuestión 47, artículo 8 de la II-II de la Suma teológica. Es el conocido método de ver, juzgar y actuar, hoy empleado en múltiples investigaciones de carácter práctico (Aquino, 2001). El criterio de juicio fundamental usado por esta metodología es la realidad misma de las cosas, entendida en su noción metafenoménica² ${ }^{2}$.

La noción de dignidad humana —en la que la Corte soporta el pluralismo social, según se ha indicado en el apartado anterior- fue incorporándose a las distintas cartas fundamentales de los países, proclamadas a lo largo del siglo pasado,

2 Este criterio fundamental de juicio ha pasado la aduana de la historia. Empero, con el giro filosófico de la Modernidad el eje de gravedad del pensamiento filosófico y científico pasó del ser al hombre, quien "se sitúa en el centro del universo de los entes y se constituye de algún modo en medida a la que aquellos han de sujetarse para poder pasar y ser tenidos por tales. El hombre es entendido en su núcleo esencial como sujeto para el que el ente se convierte en objeto de pensamiento" (Colomer, 1986, p. 14). Cobra vida entonces una manera de entender la realidad, el mundo, el conocimiento y las cosas en general, para la cual el eje fundamental en el problema gnoseológico es el sujeto que piensa la realidad. Por tanto, esta no existe con independencia de aquel (Gilson, 1952, p. 157). En el ámbito jurídico esta filosofía se ha traducido en que las distintas ramas del derecho se articulan en torno a un núcleo epistemológico dado por el derecho constitucional, en el que la interpretación de los tribunales constitucionales se ha vuelto determinante, y una teoría general del derecho puesta a su servicio, sin más referente que los fenómenos sociales y una racionalidad humana que pretermite cualquier análisis de carácter ontológico. 
Édgar Antonio Guarín Ramírez, Luisa Fernanda Olarte López, Juan Sebastián Garzón Barrera El pluralismo social en la jurisprudencia de la Corte Constitucional colombiana y sus efectos en la realización efectiva de los derechos

concomitantemente con la recepción de los denominados derechos humanos, en virtud de la relación que existe entre estos conceptos. Hoy se aceptan un grupo de derechos como inherentes a la persona, entre ellos el más importante, la libertad. Ello en atención a la íntima relación que, como se ha dicho, guardan entre sí tales derechos y la dignidad que les sirve de fundamento. De allí que los derechos fundamentales no sean más que derechos humanos puestos en la Constitución. Empero, esa noción de dignidad no tiene referente real más que el que aporta el fenómeno social o incluso las concepciones personales de los jueces que, como afirma Mora Restrepo (2009, p. 158), en ocasiones hacen uso de ropajes justificativos para hacerlas ver como válidas ante el conglomerado social. Se ha levantado así una ciencia jurídica que en el ámbito constitucional se caracteriza por ser "sospechosamente inhumana y muy poco práctica” (Herrera, 2016, p. 206), según la cual, ser libre es ser autónomo, lo que implica ser coherente con las propias convicciones - no importa si preservan o dañan - y considerar a los otros y al ordenamiento jurídico como "límites" o "barreras".

La noción de pluralismo social desarrollada por la Corte Constitucional se corresponde con una concepción libertaria, según ella misma lo ha afirmado, cuya base es un individualismo tal, que hay contraposición de unos con otros y la realidad social no tiene un orden propio que haya que respetar (Pieper, 2001, p. 126), lo cual contraría la evidencia. Ese individualismo ocasiona una ruptura entre lo individual y los social, que tiene a la base una antropología licantrópica que ha demostrado su fracaso histórico. El orden, que es uno de los aspectos más importantes del bien común, ha dejado de ser el medio dentro del cual es posible vivir la libertad plenamente y se ha convertido en un límite a la libertad de elección: límite que hoy fácilmente se franquea.

Subyacen a esta concepción una visión abstracta del hombre; una noción de dignidad que, si bien refiere a aspectos de lo humano, no da cuenta de su totalidad; una intelección de la libertad que la reduce al libre albedrío o capacidad de elección pretermitiendo el hecho de que el acto libre es el acto humano, esto es, aquel producto de la inteligencia y la voluntad, y por tanto, imposible de realizar en cuanto tal cuando se hace abstracción de la verdad y del bien, y una comprensión del derecho y de la decisión judicial al servicio de los intereses individuales con desconocimiento del 
bien común (Villey, 1979, p. 178). La consecuencia de esto es un "vaciamiento del yo, reduciéndolo a una especie de fantasma privado de densidad humana y existencial" (Gevaert, 1987, p. 33).

Frente a posturas que exacerban lo individual, se puede verificar en la realidad que el otro no es un límite sino un alter ego — otro como yo-, con quien existe la posibilidad de encuentro, de unidad, de convivencia pacífica, porque gracias a la naturaleza racional que se comparte, en todos los seres humanos hay una apertura a la búsqueda de la verdad, y a partir de esta, del bien, de aquello que preserva y que posibilita en cada uno la realización propia de manera auténtica y la contribución a la realización de los otros.

Las problemáticas existentes hoy en Colombia son generadas en buena parte por esta ruptura entre lo individual y lo social, entre el libre desarrollo de la personalidad y el bien común: la confrontación social a todo nivel —empezando por la propia familia-, la inseguridad, la ausencia de conciencia sobre la importancia del orden social, el irrespeto a la autoridad, la insolidaridad social, de las cuales dan cuenta día a día los medios de comunicación social. Es urgente e imperioso rehabilitar esos aspectos que históricamente han estructurado los derechos, dentro de los que sobresale como fundamento la realidad misma de la persona humana que, en cuanto tal, es digna. Por eso, si bien en el realismo filosófico-jurídico la dignidad es un concepto complejo, no fácilmente delimitable en una única definición, no por ello se convierte en un concepto vacío - flatus vocis - que pueda ser llenado de cualquier forma (Melendo y Millán Puelles, 1996, p. 7).

Ello es así por cuanto la noción básica y más fundamental del realismo como sistema de pensamiento es la de ceñimiento o fidelidad a la realidad, que es la fuente de la verdad. Hay una noción clásica de lo real que, a diferencia de lo que acontece con el factualismo norteamericano y escandinavo, trasciende el ámbito fenoménico, en la que la realidad refiere al ser que supera lo manifiesto y lo que aparece. "No es solo la operación sino la configuración profunda que la sustenta; ni tampoco es, solamente, el ocurrir, sino ese intangible 'para qué' y 'hacia dónde' de la ocurrencia" (Herrera, 2016, p. 221). Este es un criterio de juicio fundamental para valorar el alcance que la Corte Constitucional le ha venido dando al pluralismo social, toda 
Édgar Antonio Guarín Ramírez, Luisa Fernanda Olarte López, Juan Sebastián Garzón Barrera El pluralismo social en la jurisprudencia de la Corte Constitucional colombiana y sus efectos en la realización efectiva de los derechos

vez que, como señala Marquínez Argote (2006, p. 33), históricamente los términos realidad y verdad son inseparables.

Dentro de la realidad del ser humano está su naturaleza social. La noción de persona como "individuo de naturaleza racional", si bien evidencia que cada uno es único e irrepetible, diverso y diferente, también muestra que nuestro ser subsistente se realiza en comunión con los otros. Esta nota esencial del ser humano se convierte en exigencia porque lo real exige, o en otras palabras, el ser demanda algo que le es debido: un deber no meramente eidético, construido a priori como aconteció con el racionalismo kantiano, sino soportado en lo real. En el obrar humano esta realidad se corresponde con la condición humana, que tiene sus exigencias en términos de realización del obrante. Por ende, el ser humano es individuo, pero a la vez coexiste con los otros. Por eso la realidad muestra la pluralidad que hay entre los seres humanos, a la vez que exige que cada individuo contribuya al bien común. Esto es, a aquello que le pertenece a la comunidad en cuanto tal y que ha de ser dado por cada persona que la integra con prioridad sobre cualquier otro tipo de justicia por las implicaciones que tiene su afectación (Pieper, 2001, p. 123). Ello hace parte también de la dignidad humana.

Así pues, la libertad, más que la posibilidad de vivir como cada uno quiera - que sigue siendo real en cuanto el hombre tiene libre albedrío-, consiste en vivir y obrar humanamente. Esto significa poner la inteligencia y la voluntad al servicio de sus objetos, la verdad y el bien, no solo en el plano individual, sino también en el marco de las relaciones sociales. En esto consiste la verdadera autonomía y capacidad de autodeterminación de la persona:

No $[\ldots]$ en que el individuo racional tenga un total dominio de su ser y de su obrar, pues nada puede ser causa de sí mismo en sentido absoluto, en cuanto no es posible constituir el propio ser por medio del obrar. Dicha autodeterminación se refiere solo al orden operativo, no entitativo; y, en el orden operativo, además, concierne a la elección de los medios y no al fin o a la ejecución de las acciones. (Lombo, 2001, pp. 309-310) 
Los efectos prácticos de un concepto de pluralismo social enraizado en la dignidad reducida a una libertad sin referente real son evidentes y pueden sintetizarse en dos consecuencias: daño personal y daño social, sin que pueda haber entre uno y otro una diferencia tal que se pueda afirmar que lo uno no incide en lo otro. La naturaleza social del hombre imposibilita esta ruptura. Además, es palmaria la contradicción lógica de una noción de libertad reducida al "vivir como cada uno quiera", pero que a la vez exige, sin violar el régimen jurídico, respetar que el otro también pueda vivir como quiera. Si se es consecuente con una noción de la libertad así, sin ningún sentido o criterio de perfección objetivo — como lo ha dicho la Corte-, entonces no tiene lógica que haya límites. Y menos aún si dichos límites vienen dados por un ordenamiento jurídico cuyos principios y criterios de acción son objetivos. No sucede lo mismo con la noción de libertad como la capacidad que tiene el ser humano de "obrar humanamente", y no simplemente de vivir como quiera (Gevaert, 1987, p. 188).

Hablar de pluralidad y no de pluralismo, como lo hace el realismo, se aviene más a lo que es el ser humano, esto es, a su verdad como persona y a la especial excelencia que encierra su dignidad. Es propia de la sociedad política, como de cualquier comunidad humana, la pluralidad; y su negación conduce a la aniquilación misma de dicha sociedad por cuanto "no se hace una comunidad política partiendo de individuos semejantes" (Aristóteles, 2002, p. 67). Pero es en el marco de dicha pluralidad en donde ha de desarrollarse la dimensión interpersonal de la libertad mediante la vivencia de valores compartidos. En el pluralismo defendido a ultranza esto se dificulta en sumo grado. En efecto,

[...] la libertad no existe ni puede concebirse fuera de la relación interpersonal, ya que el hombre es siempre y necesariamente ego con los demás en el mundo. Hablar de la libertad como pura subjetividad, como pura interioridad, como coherencia interior, como pura ratio, sin cuerpo y sin los demás, es ignorar la condición concreta del hombre como ser encarnado, constitutivamente orientado hacia los demás. (Gevaert, 1987, p. 212)

La significación del término pluralismo dada por el alto tribunal de lo constitucional en Colombia, al poner la dignidad como su soporte y a la vez a la libertad como su eje 
Édgar Antonio Guarín Ramírez, Luisa Fernanda Olarte López, Juan Sebastián Garzón Barrera El pluralismo social en la jurisprudencia de la Corte Constitucional colombiana y sus efectos en la realización efectiva de los derechos

fundamental — con la significación que a esta se le ha dado, anotada en los párrafos anteriores-, tiene importantes efectos para la materialización de los derechos de los otros y de la sociedad políticamente organizada. En la filosofía política y jurídica clásica bienes como la seguridad y el orden eran considerados verdaderos derechos debidos por los miembros de la comunidad y exigibles por parte de ella. La relación de justicia que nace de esta relación entre la comunidad, sus derechos en cuanto comunidad y sus integrantes se llama justicia general. La misma Corte Constitucional ha reconocido que estos bienes constituyen límites a las libertades. No obstante, invocando el pluralismo ha hecho prevalecer las segundas en detrimento de los primeros. La cuestión no es qué prevalece sobre qué, sino cómo pueden acompasarse armónicamente las dos cosas sobre la base de una libertad mejor entendida. Ya desde la escolástica se afirmaba con realismo que, si bien el hombre es un ser social y político por naturaleza, "[...] no se ordena a la comunidad política según todo él y según todo lo suyo" (Aquino, 2001, I-II, 21.4 ad. 3). Esto significa que no se trata de contraponer lo particular y lo comunitario, sino de hacerlos confluir para que, creciendo la comunidad, crezca cada uno de sus miembros. Esta ha sido una dinámica relacional entre la parte y el todo que ha mostrado buenos frutos históricos porque está en medio de las tendencias extremas del individualismo y el colectivismo. Por ende, cada integrante del cuerpo social tiene la posibilidad y la responsabilidad de tomar su propia vida en sus manos, pero sin afectar el bien común político. Actualmente el modelo de justicia utilitarista, que piensa que una sociedad política es tanto más justa cuanto más alto es el número de bienes o deseos de los ciudadanos que se consigue producir y garantizar, está siendo superado en el mundo (Chalmeta, 2002, p. 19).

El principio del bien común politico aportado por el realismo es un foco que puede arrojar luz frente a la actual crisis y decadencia de un Estado dirigido por el impulso de una doctrina jurídico-política de afirmación a ultranza de libertades individuales dejando de lado la inseparable relación entre el bien y la justicia. El bien común, compilador de valores de coexistencia que son auténticos derechos de la comunidad - como la unidad de la paz, la seguridad, el orden, la solidaridad, entre otros-, no sacrifica los derechos personales del individuo, entre ellos el uso legítimo de su libertad, y a la vez los acompasa con los derechos de la comunidad cuyo respeto representa un bien para todos. Una sociedad política es justa cuando hay 
respeto y promoción del bien de cada hombre, ya que cada persona ha de ser considerada como un valor absoluto, un "todo" metafísico y moral. Pero a la vez, es importante el bien de la sociedad política en cuanto tal porque de ella depende todo hombre, incluso para subsistir.

\section{Discusión}

En la actualidad se recurre frecuentemente a la dignidad humana con fines retóricos, ideológicos o políticos. La cuestión de fondo, más que analizar ese uso, es revisar si dicho término se corresponde con una cualidad real en el ser humano. Si existe tal realidad, no es posible prescindir de ella, como al parecer lo hace la jurisprudencia de la Corte Constitucional en materia de pluralismo social. Si se rechaza ese referente real del término dignidad, tal como hoy ocurre, el resultado es el vaciamiento de un concepto y su consecuente manipulación. Empero, aunque ello suceda, no se priva a la dignidad humana de su trascendencia en los ámbitos antropológicos y jurídicos. Si la base del pluralismo social es la dignidad humana, que es un principio básico y primario en el ordenamiento jurídico colombiano, lo mínimo que exige la naturaleza racional del juez constitucional es volver la mirada sobre la propia realidad humana para descubrir en qué consiste esa especial elevación que se llama dignidad. El pluralismo social cimentado sobre una noción de dignidad humana cuyo único referente es la propia inmanencia del sujeto que, encerrado en su yo, puede vivir como quiera genera una profunda confusión. Ante esta se abre la discusión respecto de si lo más adecuado es prescindir de dicho concepto para evitar su manipulación o,

[...] por el contrario, continuar profundizando en su significado y en sus consecuencias prácticas. Precisamente, cuando se comprende que, de la dignidad humana, y de su defensa, depende, en gran medida, el destino mismo del hombre, se puede vislumbrar la importancia de tener siempre viva y activa la reflexión en torno a la misma [sic]. (Aparisi, 2013, p. 18)

Lo que sucede es que, como lo señala el Estagirita, a veces nos pasa como a los murciélagos, a quienes les ofusca la luz del día: a nosotros a veces nos ofuscan las cosas más evidentes (Aristóteles, 1970, II, 1). 
Édgar Antonio Guarín Ramírez, Luisa Fernanda Olarte López, Juan Sebastián Garzón Barrera El pluralismo social en la jurisprudencia de la Corte Constitucional colombiana y sus efectos en la realización efectiva de los derechos

\section{ConClusiones}

La realidad personal del ser humano, que encierra una especial dignidad, pone de presente la existencia de su unicidad, irrepetibilidad e individualidad. Por eso en toda sociedad siempre va a haber diferencias. El concepto de pluralidad social cobra entonces especial importancia. En efecto, en el marco de la pluralidad se estima la diferencia como un bien, en tanto es expresión de la autonomía de las personas para determinarse en los diferentes ámbitos de su vida, a la vez que con ella se contribuye a la construcción del bien común. Así entendido, lo plural no genera ruptura entre lo individual y lo social, antes bien, crea una relación estrecha sin solución de continuidad, por cuanto el bien de una comunidad redunda necesariamente en el bien de cada uno de sus integrantes. Empero, cuando lo individual se absolutiza, como sucede con el pluralismo social en los términos desarrollados por la Corte Constitucional colombiana, y se ve al otro y al ordenamiento como límites y no como posibilidades, el corolario es la afectación de la vida social. La absolutización del yo que se vislumbra en los fallos del alto tribunal de los constitucional en Colombia la ha llevado a la consideración de la dignidad humana como un criterio que se define especialmente a partir de una noción de libertad reducida al libre albedrío - o capacidad de elección que tiene el ser humano- con indiferencia frente al bien, que deviene realizativo. Estas nociones no dan cuenta de la realidad profunda y multidimensional que se descubre en la persona humana cuando se va más allá de lo fenoménico, lo cual solamente es posible desde la filosofía. El reconocimiento de lo plural no puede significar violación de derechos de los demás; entre ellos, la vida, cuyo título va más allá de la voluntad de un legislador o de un juez, so pretexto de la defensa de la libertad. Tampoco ha de llevar a una tolerancia que se convierta en injusticia, como acontece cuando se exige tolerar conductas que afectan la vida física, emocional o sicológica de otras personas. Es la verdad la que libera al hombre, y no la libertad la que lo hace "verdadero".

\section{ReFERENCIAS}

Abellán, M. G. (1990). Obediencia al derecho y objeción de conciencia. Madrid: Centro de Estudios Constitucionales. 
Aldana, J. y Guarín, E, (2016). Los límites de la teoría del equilibrio como alternativa de solución a la cuestión de la prevalencia del poder del alto Tribunal de lo Constitucional en Colombia. Via Inveniendi et Iudicandi, 11(1), 59-82. DOI: https://doi. org/10.15332/s1909-0528.2016.0001.01

Aparisi, A. (2013). El principio de la dignidad humana como fundamento de un bioderecho global. Cuadernos de Bioética, 24(18), 201-221.

Aquino, T. de (2001). Suma teológica. Madrid: Biblioteca de Autores Cristianos.

Aristóteles (1970). Metafísica. Madrid: Gredos.

Aristóteles (2002). La politica. Bogotá: Panamericana.

Chalmeta, G. (2002). La justicia politica en Tomás de Aquino. Pamplona: Eunsa.

Comer, D. E. (1986). La filosofía alemana de Kant a Heidegger. Barcelona: Herder.

Corte Constitucional. Sentencia T-409 (8 de junio de1992).

Corte Constitucional. Sentencia C-221 (29 de abril de 1997).

Corte Constitucional. Sentencia C-309 (25 de junio de1997).

Corte Constitucional. Sentencia C-616 (27 de noviembre de 1997).

Corte Constitucional. Sentencia C-373 (15 de mayo de 2002).

Corte Constitucional. Sentencia T-881 (17 de octubre de 2002).

Corte Constitucional. Sentencia C-098 (11 de febrero de 2003).

Corte Constitucional. Sentencia T-1096 (4 de noviembre de 2004). 
Édgar Antonio Guarín Ramírez, Luisa Fernanda Olarte López, Juan Sebastián Garzón Barrera El pluralismo social en la jurisprudencia de la Corte Constitucional colombiana y sus efectos en la realización efectiva de los derechos

Corte Constitucional. Sentencia C-355 (1 de febrero de 2006).

Corte Constitucional. Sentencia T-266 (4 de abril 2006).

Corte Constitucional. Sentencia C-355 (1 de febrero de 2006).

Corte Constitucional. Sentencia T-391 (22 de mayo de 2007).

Corte Constitucional. Sentencia T-388 (28 de mayo de 2009).

Corte Constitucional. Sentencia T-1023 (10 de diciembre de 2010).

Corte Constitucional. Sentencia T-817 (1 de noviembre de 2011).

Corte Constitucional. Sentencia C-948 (3 de diciembre 2014).

Corte Constitucional. Sentencia SU-108 (3 de marzo de 2016).

Corte Constitucional. Sentencia SU-214 (28 de abril de 2016).

Gevaert, J. (1987). El problema del hombre. Salamanca: Sígueme.

Gilson, É. (1952). El realismo metódico. Madrid: Rialp.

Guarín, E. (2013). Persona y realización efectiva de derechos. Revista Iusta, 38(1), 133154. DOI: https://doi.org/10.15332/s1900-0448.2013.0038.05

Herrera, C. (2016). Aproximación a los fundamentos cientificos y filosóficos del iusnaturalismo realista de Javier Hervada. Pamplona: Eunsa.

Lombo, J. Á. (2001). La persona de Tomás de Aquino. Roma: Sanctae Crucis.

Marquínez Argote, G. (2006). Historia de la palabra realidad desde sus orígenes latinos hasta Zubiri. Bogotá: Universidad Santo Tomás. 
VIeI Revista Virtual

Via Inveniendi et Iudicandi

Melendo, T. y Millán Puelles, A. (1996). Dignidad: ¿Una palabra vacía? Pamplona: Eunsa.

Mora Restrepo, G. (2009). Justicia constitucional y arbitrariedad de los jueces. Buenos Aires: Marcial Pons.

Pieper, J. (2001). Las virtudes fundamentales. Buenos Aires: Marcial Pons.

Rodríguez, E. (2016). El pasaje del Estado y el derecho a la postmodernidad. Via Inveniendi et Iudicandi, 11(2), 11-37. DOI: https://doi.org/10.15332/s1909-0528.2016.0002.01

Villey, M. (1979). Compendio de filosofía del derecho. Pamplona: Eunsa. 